\title{
A numerical study into the longitudinal dynamic stability of the tailless aircraft
}

\begin{abstract}
Purpose - The main objective of the research is a study into a mathematical approach of a tailless aircraft dynamic stability analysis. This research is focus on investigation of influence of elevons (elevator) on stability derivatives and consequently on the aircraft longitudinal dynamic stability. The main research question is to determine if this impact should be taken into account on the conceptual and preliminary stage of the analysis of the longitudinal dynamic stability?
\end{abstract}

Design/methodology/approach - Aerodynamic coefficients and longitudinal stability derivatives were computed by Panukl (panel methods). The analysis of the dynamic stability of the tailless aircraft was made by the Matlab code and SDSA package.

Findings - The main result of the research is a comparison of the dynamic stability of the tailless aircraft for different approaches; with and without the impact of elevator deflection on the trim drag and stability derivatives.

Research limitations/implications - This paper presents research which mostly should be considered on the preliminary stage of aircraft design and dynamic stability analysis. The impact of elevons deflection on the aircraft moment of inertia was has been omitted.

Practical implications - The results of this research will be useful for the further design of small tailless Unmanned Aerial Vehicles.

Originality/value - This research reveals that in case of the analysis of a small tailless Unmanned Aerial Vehicles, the impact of elevons deflection on stability derivatives is bigger than the impact of a Mach number. This impact should be taken into consideration, especially for a phugoid mode.

Keywords Longitudinal dynamic stability, Tailless aircraft, Stability of unconventional configuration, UAV, CDF, SDSA.

Paper type Research paper

\section{Introduction}

The application of Unmanned Aerial Vehicles (UAV) has recently rapidly increased. The UAVs are used in several domains such as military, civil and space technology applications as well as for education purposes. Such a big market demand and variety of requirements create opportunities to develop and design unconventional aircraft configurations - such as tailless configuration. A flying wing UAV can successfully fly even in a turbulent atmosphere, a study about design the flying wing gust resistant Micro Aerial Vehicles is presented in (Galiński C., Mieloszyk J., (2012)). However, the tailless aircraft configuration is not only applied in UAVs but it also popular for a manned aircraft. Results of a study into the design of the tailless rocket-plane for suborbital space flights are presented in Kwiek A., Figat M. (2016) and Figat M., Kwiek A. (2017). A delta wing configuration is also very often applied in a high manoeuvrable aircraft, results of the investigation into a geometry impact on a pitch-up effect which causes the problem with aircraft stability and analysis of aircraft dynamic stability on high angles of attack was investigated in Grafton S. B. (1984). The pitching moment characterises can be change by an application of a leading edge flap on the delta wing (Rao D.M. (1979)). The problem of the dynamic stability of the flying wing aircraft designed for passengers' flights was investigated in D'Urso S. and Martinez-Val R. (2008). Results of the flight dynamics analysis of UAVs are presented in Tomac M., Stenfelt G. (2014), Esteban S., (2001), Goraj (2014). Moreover, a multi-disciplinary optimisation recently became a very popular in the aircraft design due to high computers performance capacity, the flight dynamics properties could be a constrain in the multi-disciplinary optimisation of the unconventional aircraft (Mieloszyk J., Goetzendorf-Grabowski T., (2017)). The main 
objective of the research is a study into the effective tailless aircraft dynamic stability analysis. In literature is a lot of papers about conceptual and preliminary aircraft design for a classic configuration. But not many papers about effective approaches to unconventional aircraft design. Therefore, a research on the right approach of unconventional aircraft dynamic stability analysis should be carried out. In case of a preliminary design of a classic aircraft configuration, some stability derivatives can be neglected as a derivative of a drag coefficient versus elevator deflection (Etkin and Reid (1996), Cook (2007), and Nelson (1998)). As tailless aircraft use elevons to control a pitch channel, the effect of elevons deflection on a drag coefficient is more significant than for a classic aircraft configuration. Elevons deflection modifies a wing geometry which has the biggest contribution in tailless aircraft aerodynamic characteristics. Figure 1 presents the comparison of the drag coefficient versus angle of attack for the clean tailless configuration and trim drag coefficient.

Figure 1 The comparison of the drag coefficient versus angle of attack for the clean tailless configuration and trim drag coefficient.

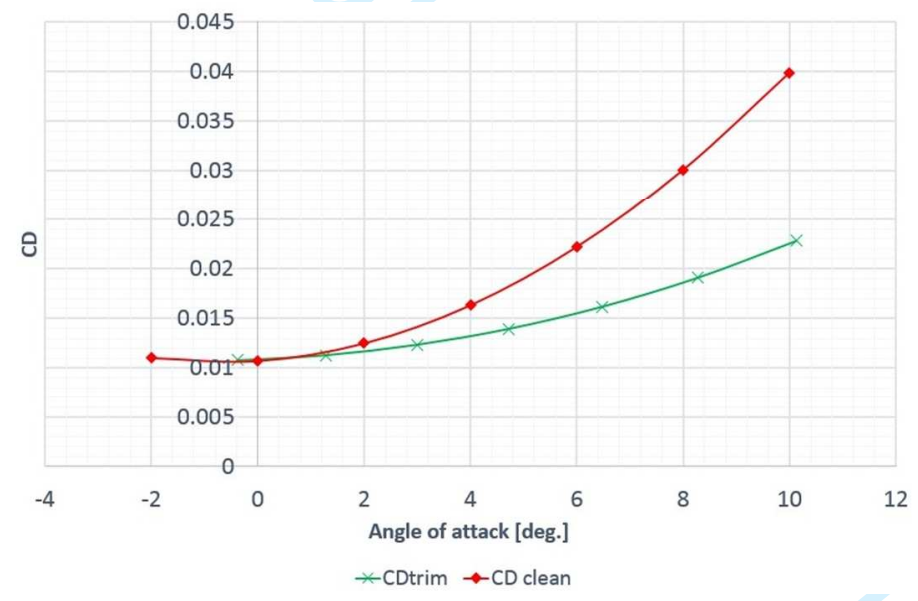

The main goal of the research is to investigate a mathematical approach to an effective analysis of a tailless aircraft longitudinal dynamic stability during a conceptual design phase. This paper presents results obtained by two different tools, a Matlab code and the SDSA package (Goetzendorf-Grabowski T., Mieszalski D., Marcinkiewicz E., (2011), SDSA (2017)). This package can be used for a dynamic stability analysis and 6DoF simulations. Three scenarios were taken into account: (1) no impact of elevons deflection on the trim drag coefficient and stability derivatives, (2) impact of elevons deflection only on the trim drag coefficient, and (3) impact of elevons deflection on the trim drag coefficient and stability derivatives.

\section{Tailless aircraft geometry}

This paper includes results of the analysis of the tailless aircraft which the layout is presented in Figure 2 . The trim condition is ensured by elevons deflection. Elevons cover $60 \%$ of the wingspan and $35 \%$ of the local wing chord, details information about it geometry is presented in Figure 1. The sign convention of elevons deflection is presented in Figure 3 , if the trailing edge move up this represents a negative elevons deflection. Reference values used for calculations are listed in Figure 1 (table in the middle). A pitching moment calculation is referred to $25 \%$ of MAC (mean aerodynamic chord), where the centre of gravity is located. The impact of elevons deflection on the aircraft moment of inertia (ly) has been omitted.

Figure 2 The aircraft layout and the most important geometrical features. 
1

2

3

4

5

6

7

8

9

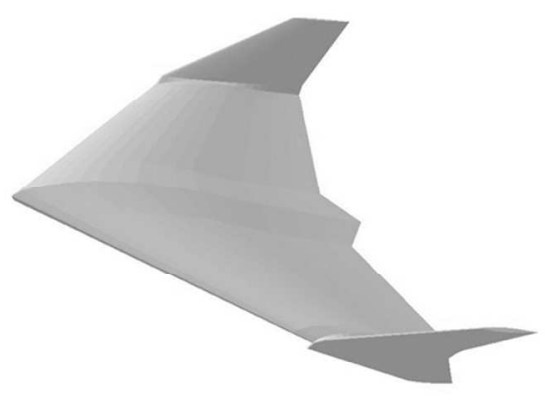

\begin{tabular}{|c|c|c|}
\hline Wingspan & 0.5 & $\mathrm{~m}$ \\
\hline Wing area & 0.227 & $\mathrm{~m}^{2}$ \\
\hline $\begin{array}{c}\text { Mean } \\
\text { aerodynamic } \\
\text { chord }\end{array}$ & 0.478 & $\mathrm{~m}$ \\
\hline Mass & 1.6 & $\mathrm{~kg}$ \\
\hline $\begin{array}{c}\text { Moment of } \\
\text { inertia (Iy) }\end{array}$ & 0.0693 & $\mathrm{~kg} \mathrm{~m}^{2}$ \\
\hline $\begin{array}{c}\text { Centre of } \\
\text { gravity } \\
25 \% \text { of MAC }\end{array}$ & 0.308 & $\mathrm{~m}$ \\
\hline
\end{tabular}

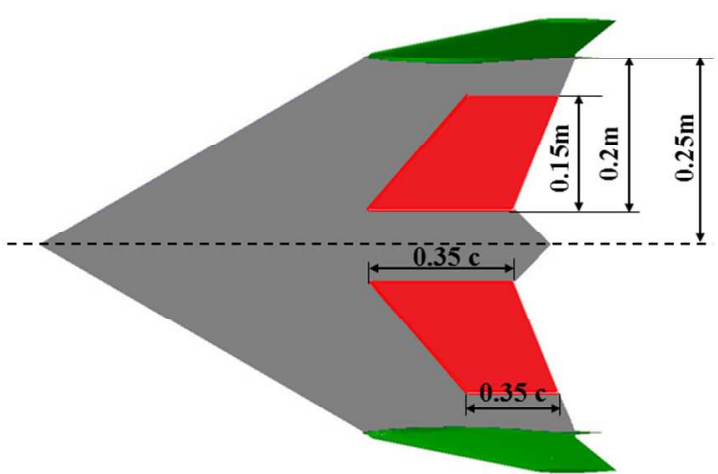

Figure 3 Elevons sing convention, the deflection angle is negative if the trailing edge moves up.

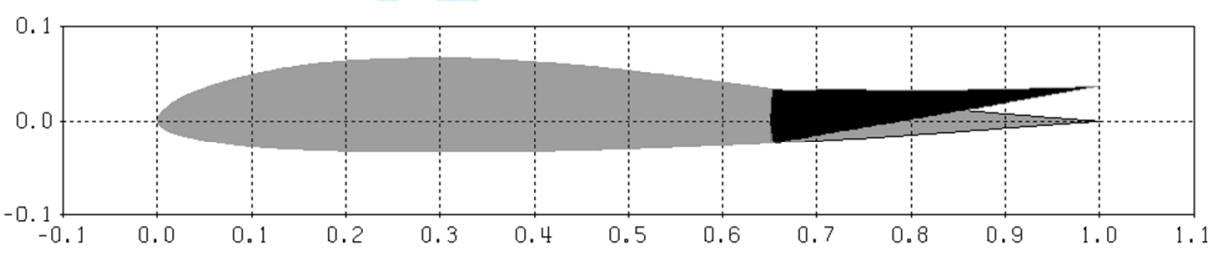

\section{Aerodynamic calculations}

Aerodynamic characteristics were computed by Panukl (Panukl, 2017) software which using a low order potential method. Moreover, Karman-Tsien compressible correction was applied. Panukl software has been used in a design of different aircraft including unconventional configurations and it is a good tool for a conceptual aircraft design phase (Mieloszyk J., Goetzendorf-Grabowski 2017, Goetzendorf-Grabowski, T. and Figat, M. (2016)). Moreover, this software includes the functionality of stability derivatives calculation. Figures 4 and 5 presenting aerodynamic characteristics for different elevons deflections. Figure 6 presented a CDF model (on the left) and an example of a pressure distribution computed by Panukl (on the right). The result of trim condition calculation is presented in Figure 7, the result takes into account the impact of elevons deflection on both trim lift coefficient and trim drag coefficient.

Figure 4 Aerodynamic characteristics for different elevons deflections: lift coefficient versus angle of attack (on the left) and drag coefficient versus angle of attack (on the right).
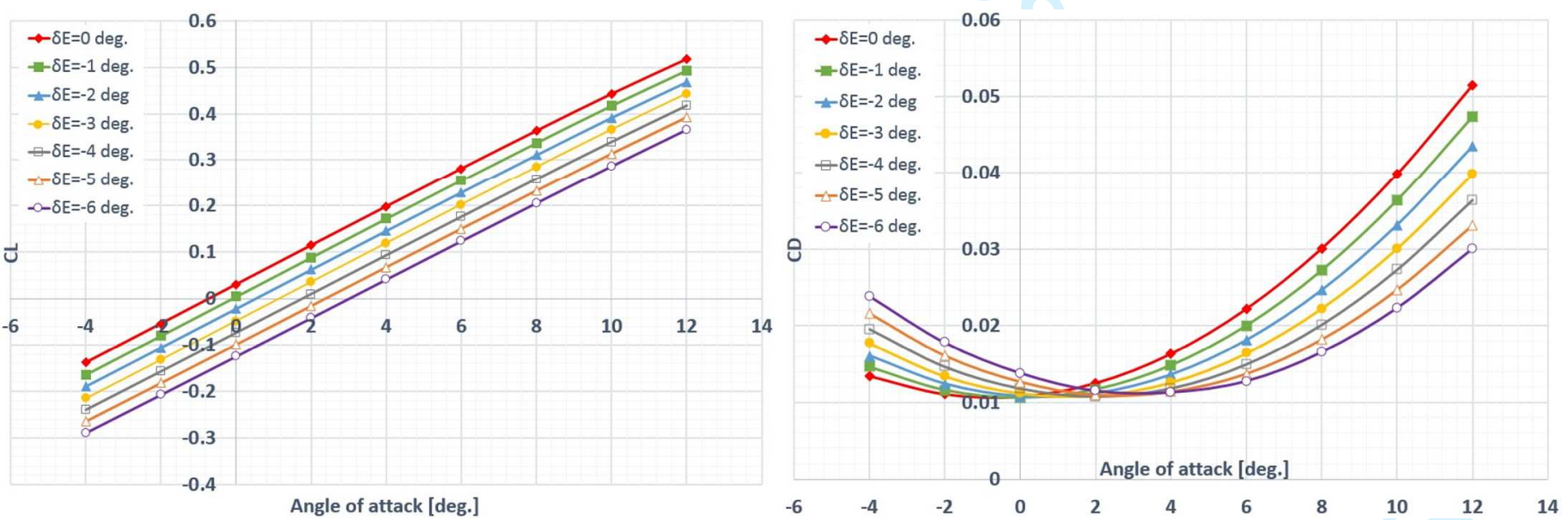

Figure 5 Aerodynamic characteristics for different elevons deflections: pitching moment coefficient versus angle of attack. 
Figure 7 The aircraft trim calculation, angle of attack, elevons deflection and thrust versus TAS if impact of elevons on the drag trim coefficient was taken into account

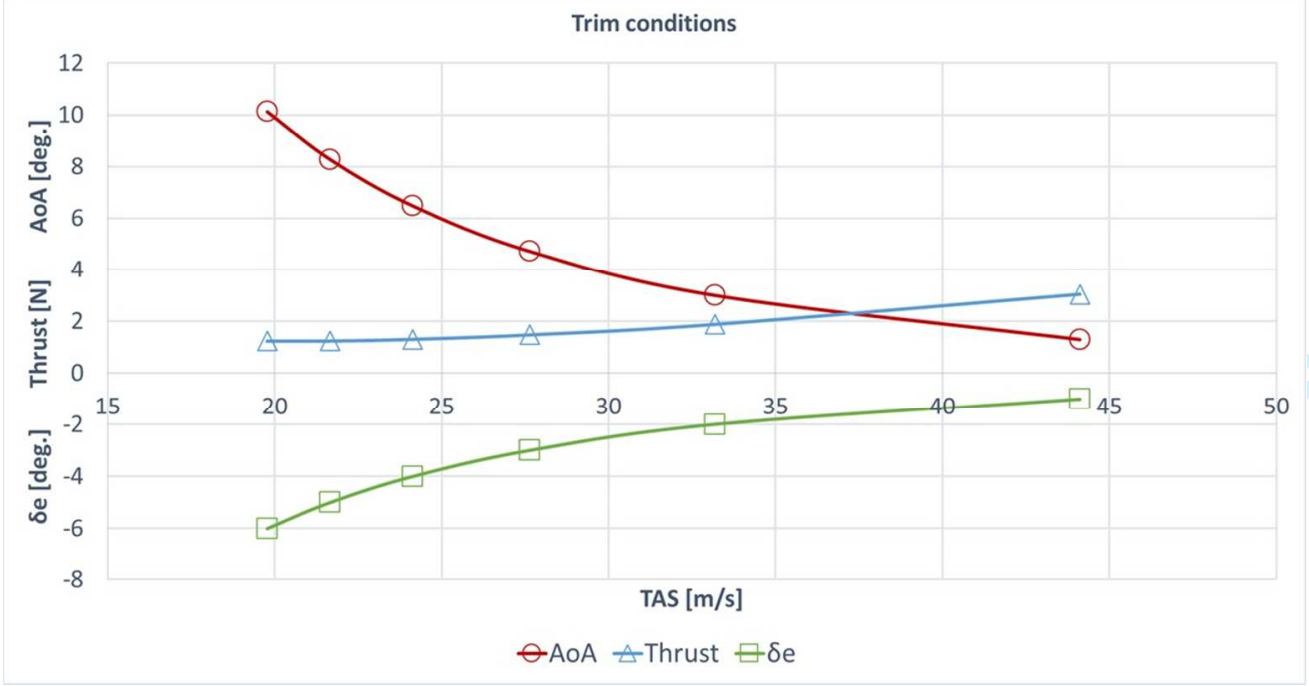

\section{Stability derivatives calculation}

It was assumed that the derivatives of the aerodynamics coefficients in respect to the pitch rate $\left(\mathrm{C}_{\mathrm{Lq}}, \mathrm{C}_{\mathrm{Dq}}, \mathrm{C}_{\mathrm{Mq}}\right)$ are constant versus the angle of attack. The dimensionless pitch rate is expressed by Eqn (1), where $Q$ is a pitch rate, MAC is a mean aerodynamic chord and $\mathrm{V}$ is an airspeed.

$\mathrm{q}=\frac{\mathrm{Q} \cdot \mathrm{MAC}}{2 \mathrm{~V}}$
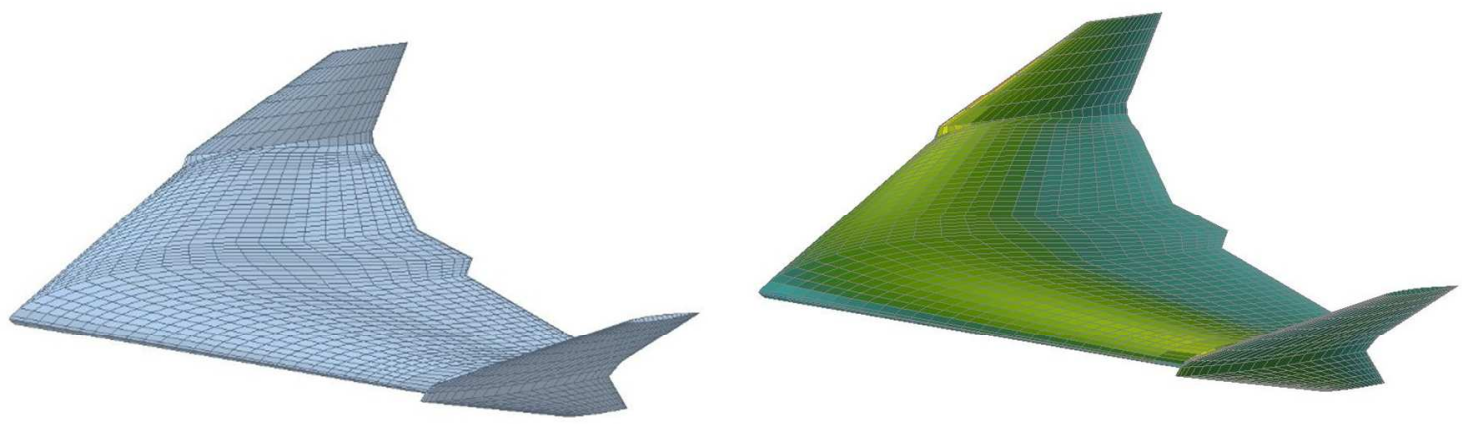
Figures 8, 10 and 12 presenting changing of CLq, CMq and CDq derivatives versus Mach number for the different aircraft configurations (different elevons deflection). The impact of the elevons deflection on all kind of the derivatives is bigger than the impact of the Mach number. Figures 9, 11 and 13 presenting elevons deflection versus CLq, CMq and CDq derivatives for $\mathrm{Ma}=0.05$, in case of $\mathrm{CLq}$ and $\mathrm{CMq}$ a nonlinear curve can be observed. Figures 14 and 15 presenting selected dimensionless derivatives: $\mathrm{xu}, \mathrm{xw}, \mathrm{zu}$ and $\mathrm{zw}$.

Figure $8 C_{\mathrm{Lq}}$ derivatives versus Ma for different elevens deflections

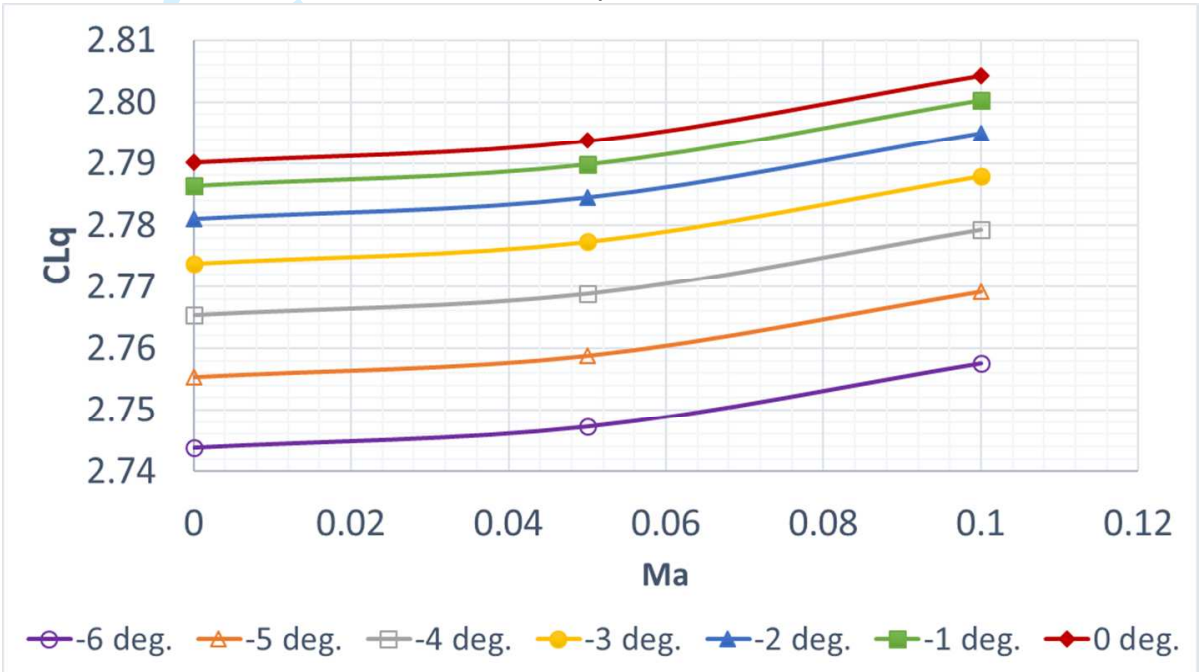

Figure 9 Elevator deflection versus CLq for Ma=0.05

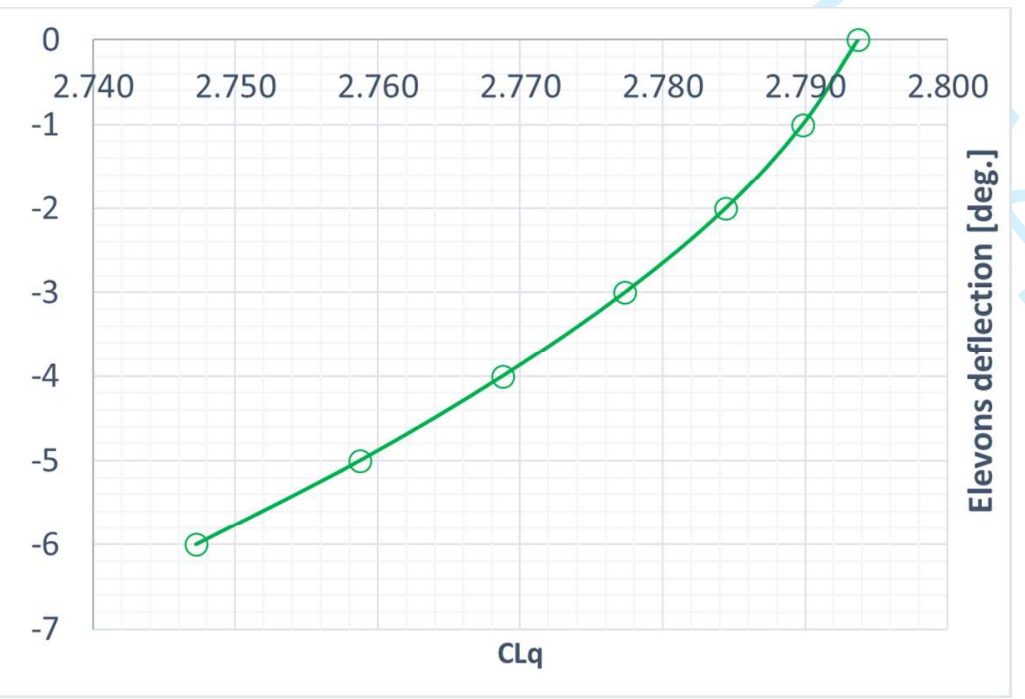

Figure $10 C_{M q}$ derivatives versus Ma for different elevens deflections 


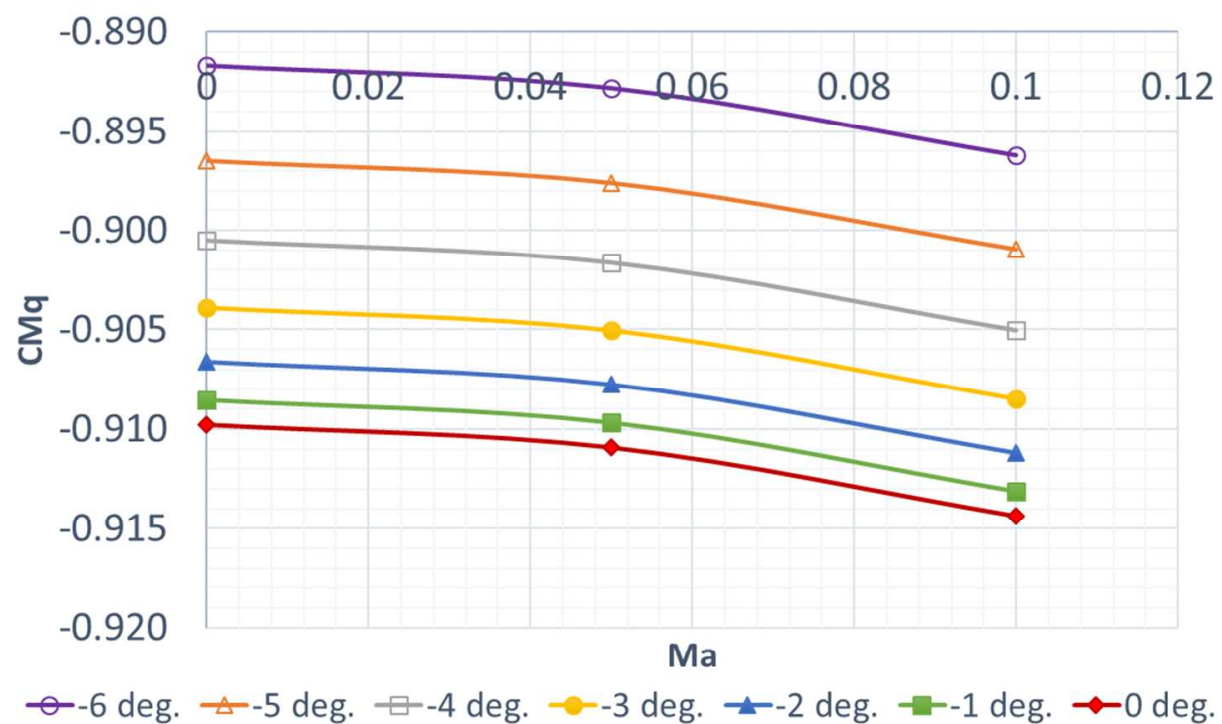

Figure 11 Elevator deflection versus $\mathrm{CMq}$ for $\mathrm{Ma}=0.05$

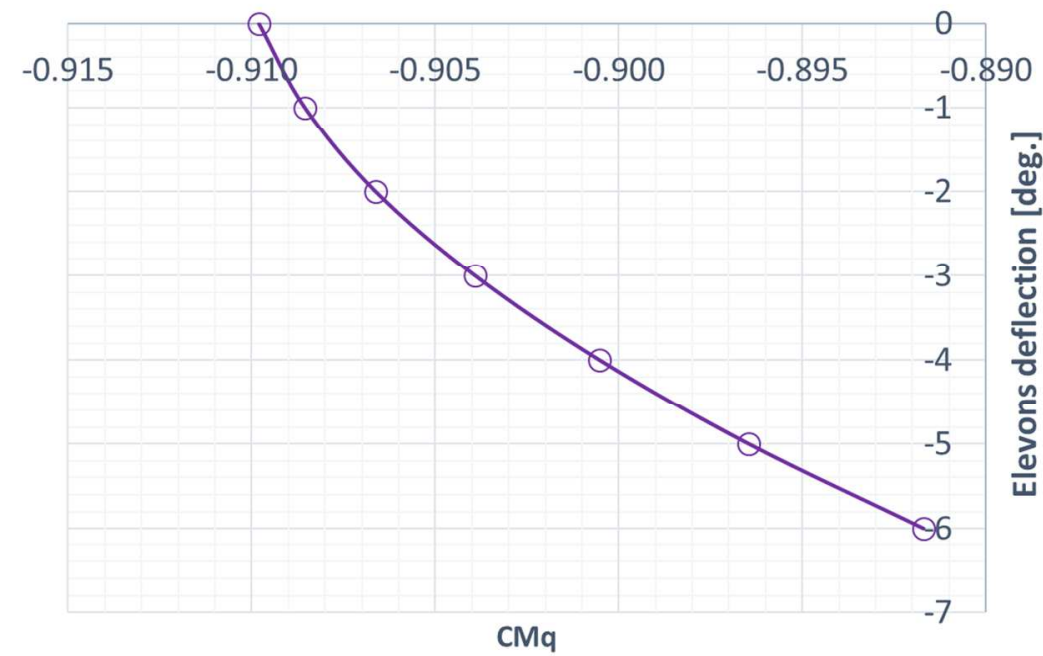

Figure $12 C_{D q}$ derivatives versus Ma for different elevens deflections 


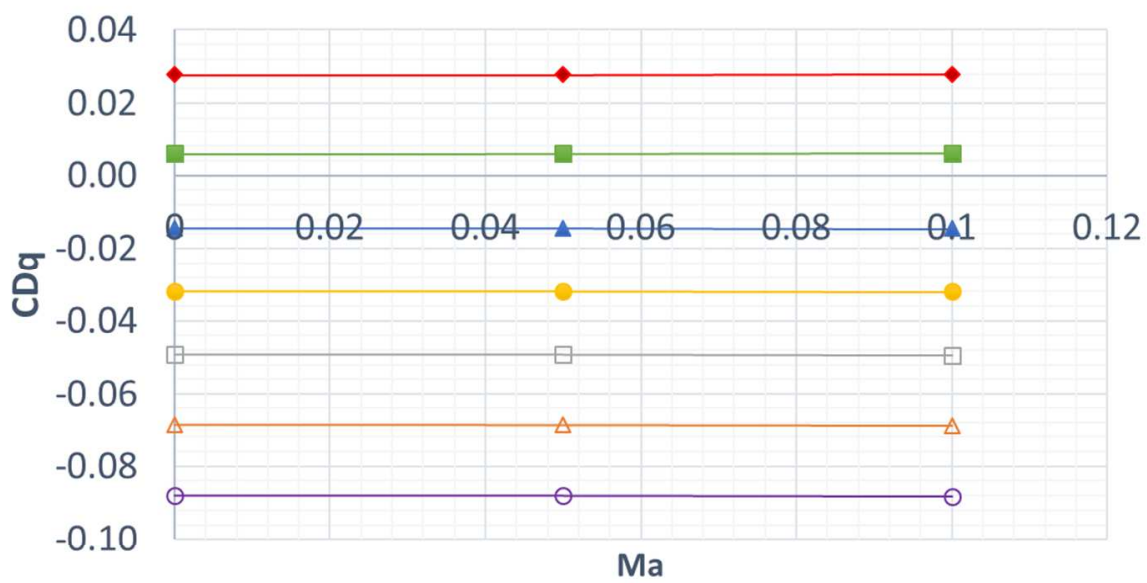

$๑-6$ deg. $\triangle-5$ deg. $\square-4$ deg. --3 deg. $\triangle-2$ deg. $\square-1$ deg. $\rightarrow-0$ deg.

Figure 13 Elevator deflection versus $\mathrm{CDq}$ for $\mathrm{Ma}=\mathbf{0 . 0 5}$

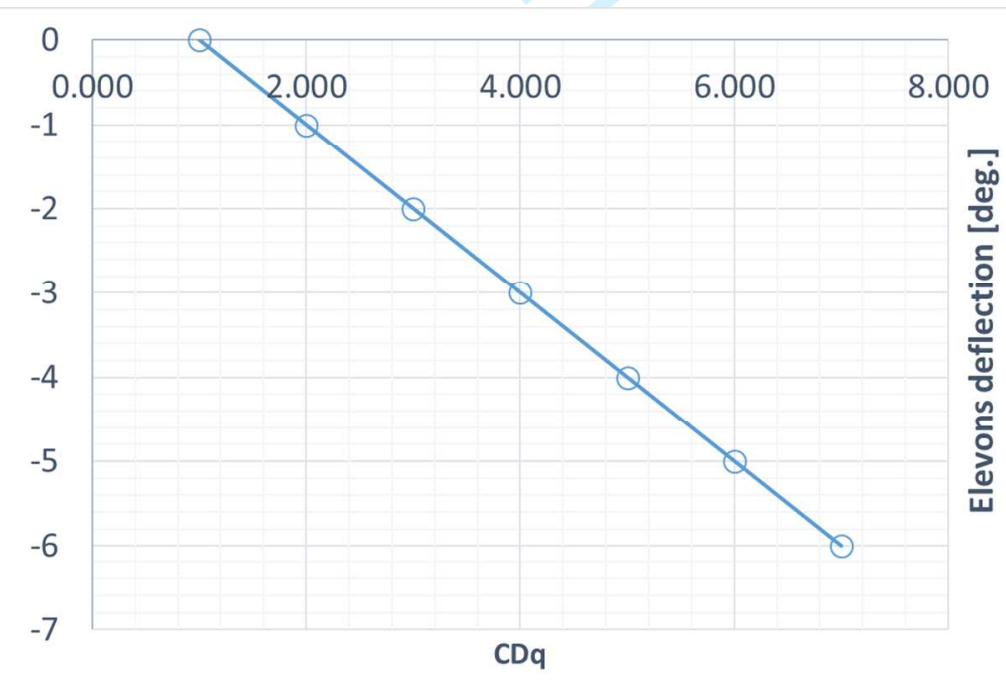

Figure 14 Elevator deflection versus $x u$ and zu dimensionless derivatives

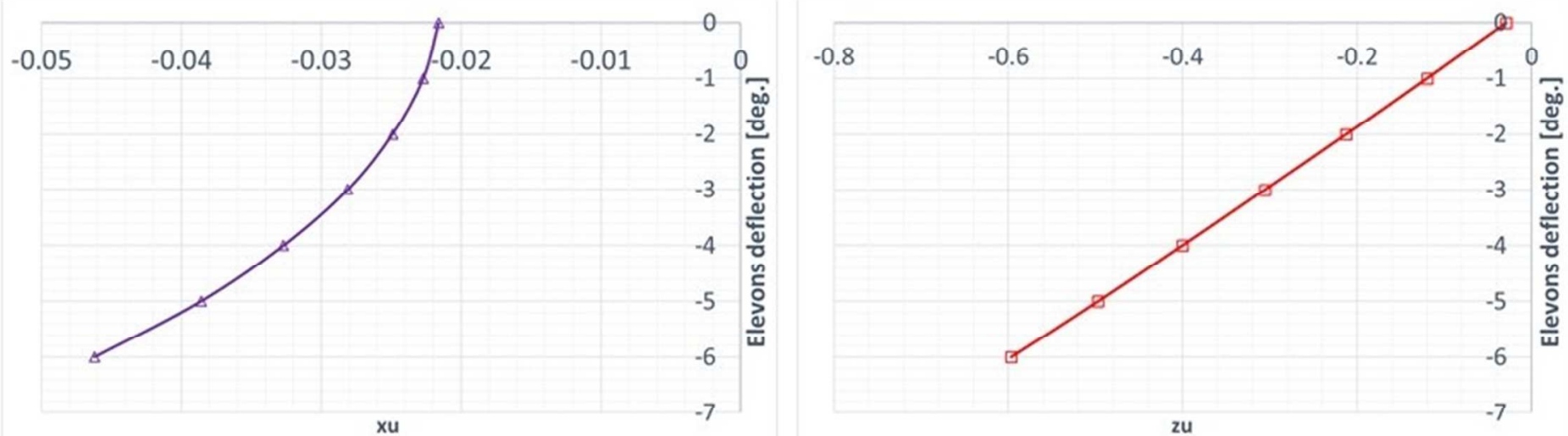

Figure 15 Elevator deflection versus $\mathbf{x w}$ and $\mathbf{z w}$ dimensionless derivatives 

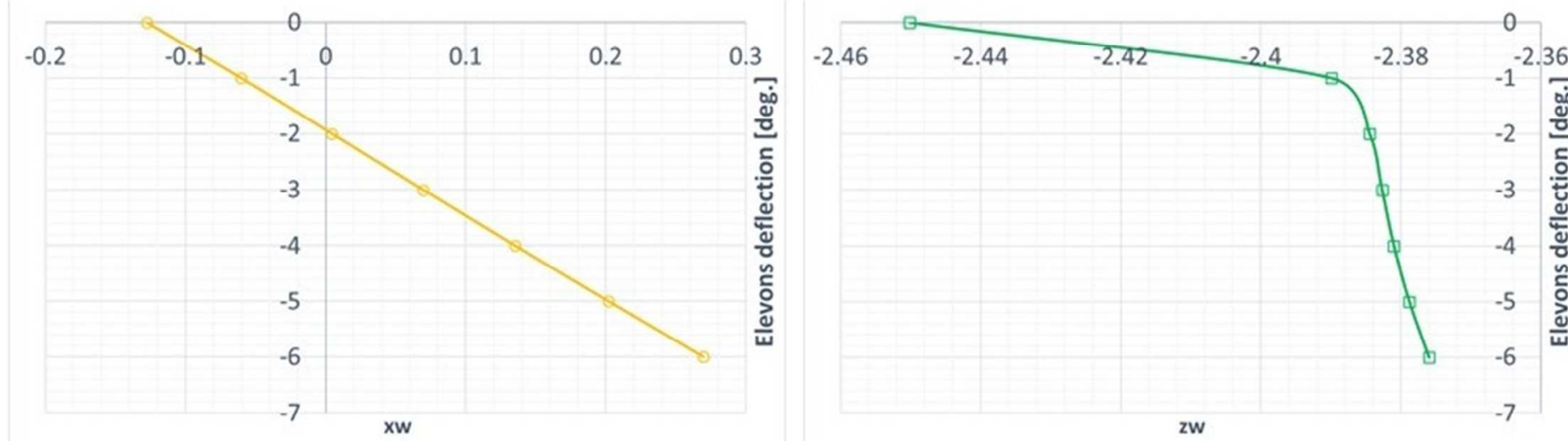

\section{Equations of motion and dynamic stability}

Description of aircraft equations of motion can be found in a literature Etkin and Reid (1996), Cook (2007), Goraj (2014), Nelson (1998). The most popular method of solving the problem of an aircraft dynamic stability is linearization equations of motion. Moreover, equations can be decoupling on a longitudinal and lateral cases. This paper presents results only for the longitudinal dynamic stability case. The equation of motion in a state space form is expressed by Eqn (2), the state vector $x$ is expressed by Eqn (3), where $A$ is a state matrix and can be expressed by Eqn(4), and $M$ is a mass matrix (Cook). In case of the longitudinal motion, the matrix $A$ is $4 \times 4$ matrix, all elements of it are expressed by Eqn (6)-(16). To solve the problem of the stability of uncontrolled motion the eigenvalue problem can be formulated by Eqn (17-18) and the solution can be express by Eqn (19). A damping ratio and undamped frequency can be expressed by Eqn (20) and (21) respectively. A period and damping halftime of aircraft's oscillations can be expressed by (22) and (23). The presented mathematical model was implemented in the Matlab to solve the problem of the tailless aircraft longitudinal dynamic stability. Figure 16 presents definition of the forces, moments, linear and angular speeds.

Figure 16 Definition of the aircraft forces, moments, linear and angular speeds
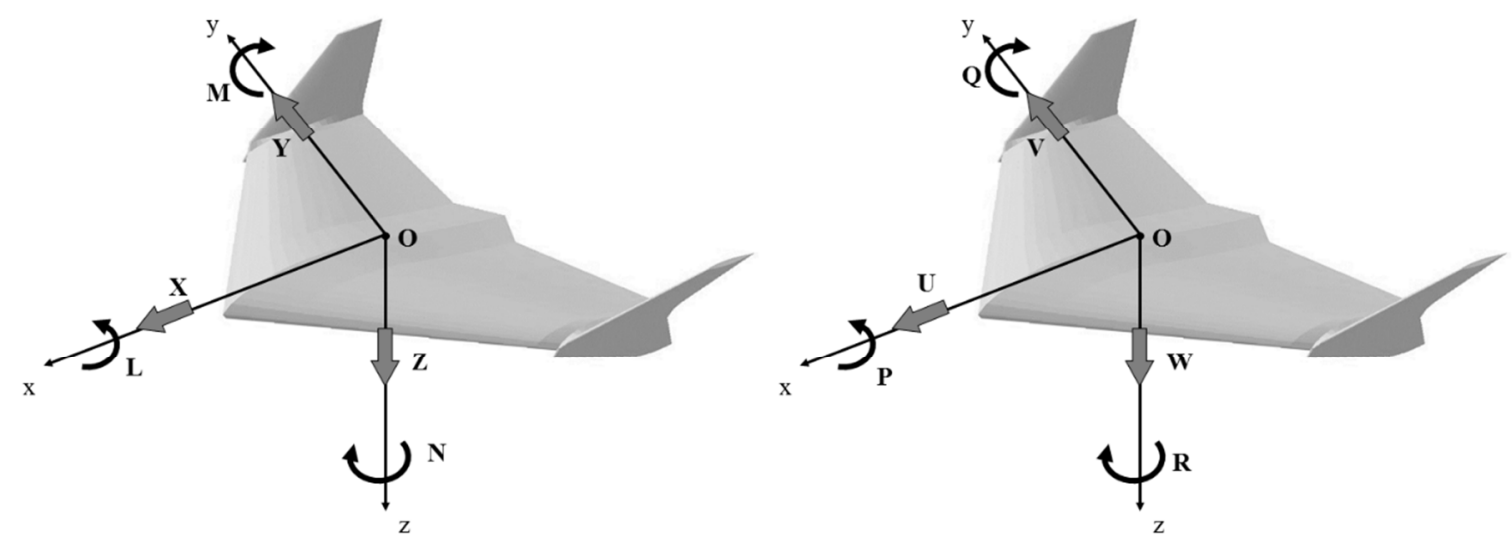

$$
\begin{aligned}
\dot{\mathrm{x}} & =\mathrm{Ax}+\mathrm{Bc} \\
x & =\left[\begin{array}{llll}
\mathrm{u} & \mathrm{w} & \mathrm{q} & \theta
\end{array}\right]^{\mathrm{T}} \\
A & =\mathrm{M}^{-1} \mathrm{~A}^{\prime}
\end{aligned}
$$


$A=\left[\begin{array}{cccc}\mathrm{a}_{11} & \mathrm{a}_{12} & \mathrm{a}_{13} & \mathrm{a}_{14} \\ \mathrm{a}_{21} & \mathrm{a}_{22} & \mathrm{a}_{23} & \mathrm{a}_{24} \\ \mathrm{a}_{31} & \mathrm{a}_{32} & \mathrm{a}_{33} & \mathrm{a}_{34} \\ 0 & 0 & 1 & 0\end{array}\right]$

$\mathrm{a}_{11}=\frac{\mathrm{x}_{\mathrm{u}}}{\mathrm{m}}$

$\mathrm{a}_{12}=\frac{\mathrm{x}_{\mathrm{z}}}{\mathrm{m}}$

$\mathrm{a}_{13}=\frac{\mathrm{x}_{\mathrm{q}}-\mathrm{mWe}}{\mathrm{m}}$

$\mathrm{a}_{14}=-\mathrm{g} \cos \theta$

$\mathrm{a}_{21}=\frac{\mathrm{z}_{\mathrm{u}}}{\mathrm{m}-\mathrm{z}_{\mathrm{w}}}$

$\mathrm{a}_{22}=\frac{\mathrm{z}_{\mathrm{w}}}{\mathrm{m}-\mathrm{z}_{\mathrm{w}}}$

$\mathrm{a}_{23}=\frac{\mathrm{z}_{\mathrm{q}}+\mathrm{u}_{0} \mathrm{~m}}{\mathrm{~m}-\mathrm{z}_{\dot{\mathrm{w}}}}$

$\mathrm{a}_{24}=-\mathrm{g} \sin \theta$

$\mathrm{a}_{31}=\frac{1}{\mathrm{I}_{\mathrm{y}}}\left[\mathrm{M}_{\mathrm{u}}+\frac{\mathrm{M}_{\dot{\mathrm{w}}} \mathrm{Z}_{\mathrm{u}}}{\mathrm{m}-\mathrm{Z}_{\mathrm{w}}}\right]$

$\mathrm{a}_{32}=\frac{1}{\mathrm{I}_{\mathrm{y}}}\left[\mathrm{M}_{\mathrm{w}}+\frac{\mathrm{M}_{\mathrm{w}} \mathrm{Z}_{\mathrm{w}}}{\mathrm{m}-\mathrm{Z}_{\mathrm{w}}}\right]$

$\mathrm{a}_{33}=\frac{1}{\mathrm{I}_{\mathrm{y}}}\left[\mathrm{M}_{\mathrm{q}}+\frac{\mathrm{M}_{\dot{\mathrm{w}}}\left(\mathrm{Z}_{\mathrm{q}}+\mathrm{u}_{0} \mathrm{~m}\right)}{\mathrm{m}-\mathrm{Z}_{\mathrm{w}}}\right]$

$x(\mathrm{t})=\mathrm{x}_{0} \mathrm{e}^{\lambda \mathrm{t}}$

$(\mathrm{A}-\lambda \mathrm{I}) \mathrm{x}_{0}=0$

$\lambda=\xi+$ in

$\zeta_{\mathrm{d}}=-\frac{\xi}{\sqrt{\xi^{2}+\eta^{2}}}$

$\omega_{\mathrm{nd}}=\sqrt{\xi^{2}+\eta^{2}}$

$T=\frac{2 \pi}{\eta}$

$\mathrm{T}_{1 / 2}=-\frac{\ln 2}{\xi}$

\section{Results}

Three scenarios were taken into consideration: (1) no impact of elevons deflection on trim drag coefficient and stability derivatives, (2) impact of elevons deflection only on a trim drag coefficient, (3) impact of elevons deflection on trim drag coefficient and stability derivatives. The scenario, when there is no elevons impact on the trim drag coefficient and stability derivative, will be named as a standard case. Table 1 presents the comparison of the scenario (2) and scenario (3) in case of short period calculation by Matlab code. The biggest difference is for $\delta e=-6$ and $T_{1 / 2}$ and is equal to $-1.35 \%$ which can be summarized as a negligible impact. Table 2 presents the comparison of the scenario (2) and scenario (3) in case of phugoid calculation by Matlab code. The biggest difference is for $\delta e=-6$ and damping ratio and is equal to $26.03 \%$ which can be summarized as a significant impact. Figure 8 and Figure 9 show the results of the time to half and 
damping ratio respectively for the phugoid mode, those results were calculated by the Matlab code. The damping ratio is smaller for a standard case and this difference between the standard case and results with the deflected elevator increasing when the elevons deflection is higher.

Table 1 Results of short period calculation by the Matlab code

\begin{tabular}{|c|c|c|c|c|c|}
\hline \multicolumn{2}{|c|}{ Trim condision } & \multicolumn{4}{|c|}{$\begin{array}{l}\text { Short period - values in this table presenting a difference between scenario (2) and scenario } \\
\text { (3) expressed in \% }\end{array}$} \\
\hline Se [deg.] & TAS [m/s] & Period & $T_{1 / 2}$ & $\omega_{\text {nd }}$ & $\zeta_{\mathrm{d}}$ \\
\hline-1 & 44.1 & $0.30 \%$ & $0.00 \%$ & $-0.27 \%$ & $0.25 \%$ \\
\hline-2 & 33.2 & $0.45 \%$ & $-0.10 \%$ & $-0.39 \%$ & $0.45 \%$ \\
\hline-3 & 27.6 & $0.45 \%$ & $-0.24 \%$ & $-0.37 \%$ & $0.59 \%$ \\
\hline-4 & 24.1 & $0.31 \%$ & $-0.49 \%$ & $-0.21 \%$ & $0.70 \%$ \\
\hline-5 & 21.7 & $0.06 \%$ & $-0.88 \%$ & $0.06 \%$ & $0.80 \%$ \\
\hline-6 & 19.8 & $-0.34 \%$ & $-1.35 \%$ & $0.45 \%$ & $0.86 \%$ \\
\hline
\end{tabular}

Table 2 Results of phugoid calculation by the Matlab code

\begin{tabular}{|c|c|c|c|c|c|}
\hline \multicolumn{2}{|c|}{ Trim condition } & \multicolumn{4}{|c|}{$\begin{array}{l}\text { Phugoid - values in this table presenting a difference between scenario (2) and scenario (3) } \\
\text { expressed in \% }\end{array}$} \\
\hline Se [deg.] & TAS $[\mathrm{m} / \mathrm{s}]$ & Period & $\mathrm{T}_{1 / 2}$ & $\omega_{\text {nd }}$ & $\zeta_{\mathrm{d}}$ \\
\hline-1 & 44.1 & $0.01 \%$ & $1.50 \%$ & $-0.03 \%$ & $-1.49 \%$ \\
\hline-2 & 33.2 & $0.01 \%$ & $4.74 \%$ & $-0.05 \%$ & $-4.99 \%$ \\
\hline-3 & 27.6 & $0.01 \%$ & $8.76 \%$ & $-0.04 \%$ & $-9.54 \%$ \\
\hline-4 & 24.1 & $-0.02 \%$ & $12.89 \%$ & $-0.02 \%$ & $-14.82 \%$ \\
\hline-5 & 21.7 & $-0.06 \%$ & $16.97 \%$ & $0.02 \%$ & $-20.49 \%$ \\
\hline-6 & 19.8 & $-0.12 \%$ & $20.69 \%$ & $0.08 \%$ & $-26.03 \%$ \\
\hline
\end{tabular}

Figure 17 Results of time to half for phugoid obtained by the Matlab code 


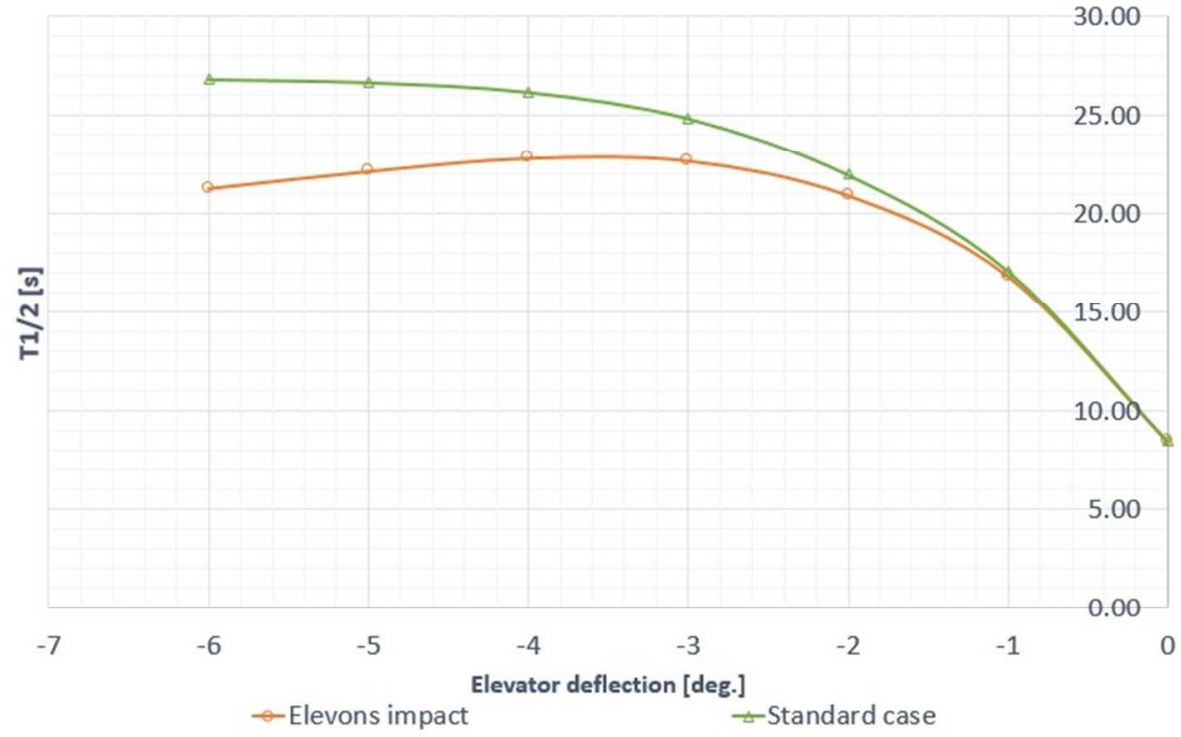

Figure 18 Results of damping ration for phugoid obtained by the Matlab code

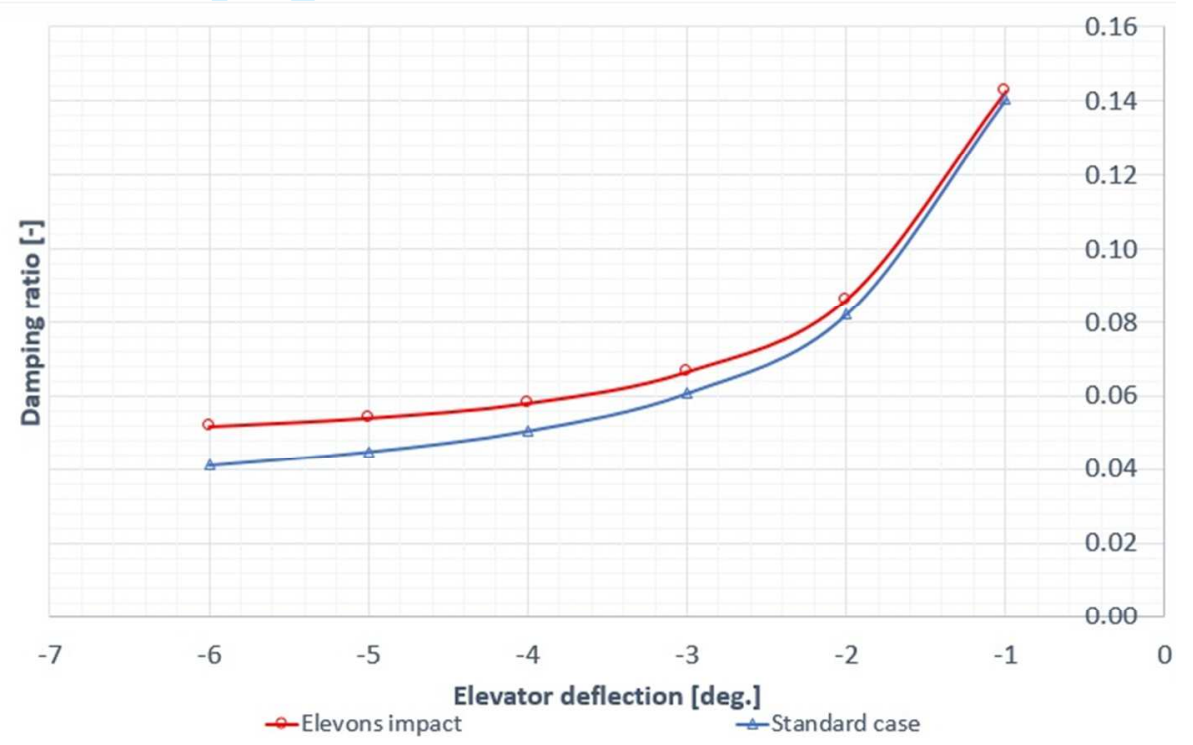

The second part of this investigation, was a simulation in SDSA software which allows on performing 6DoF simulation, however only the longitudinal modes were investigated. The examples of time history analysis are presented in Figures 19 and 20. The summary of the SDSA results and the comparison with Matlab results are presented in Table 3 and Table 4. The results for the short period mode is presented in Table 3, in case of SDSA results, the biggest difference can be noticed between scenario (1) and (3), especially for the time to half damping and damping ratio. The results for the phugoid mode are presented in Table 4, in case of SDSA results, the biggest difference can be noticed between scenario (1) and (3), especially for the time to half damping and damping ratio. Likewise, in the Matlab results, the biggest difference can be noticed for the phugoid mode. The comparison between Matlab results and SDSA results shows that again the biggest difference can be noticed for the phugoid mode.

Figure 19 Results of the time history analysis of the phugoid mode for $\delta e=-4$ computed by SDSA, the case of no impact of elevons on trim drag 


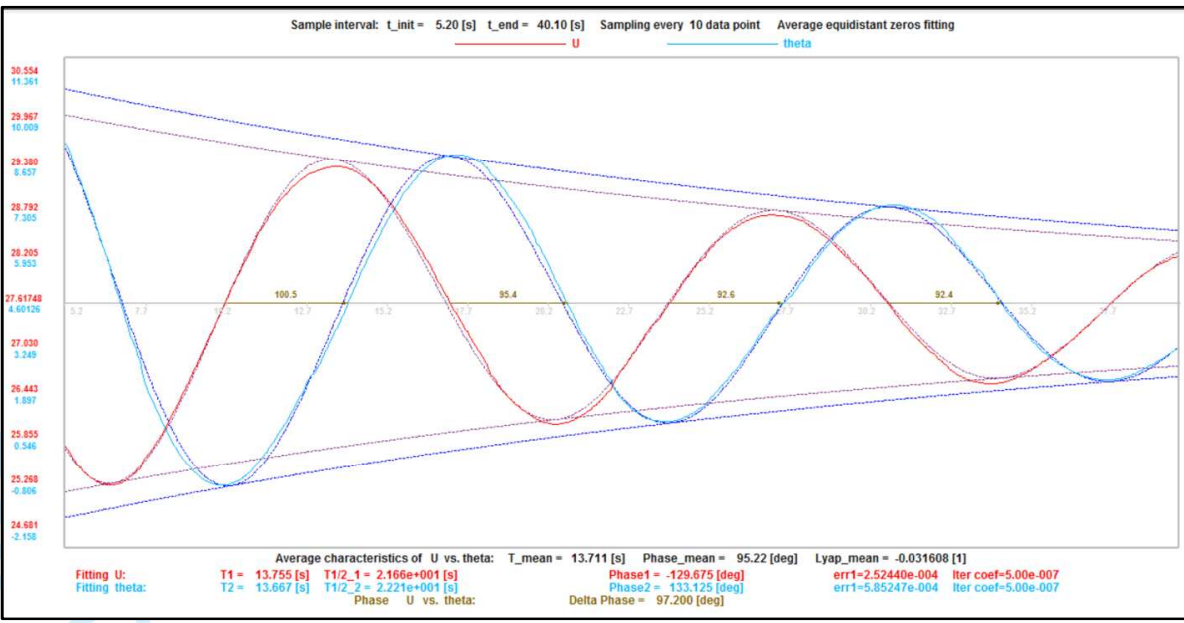

Figure 20 Results of the time history analysis of the phugoid mode for $\delta e=-4$ computed by SDSA, the case of impact of elevons on trim drag

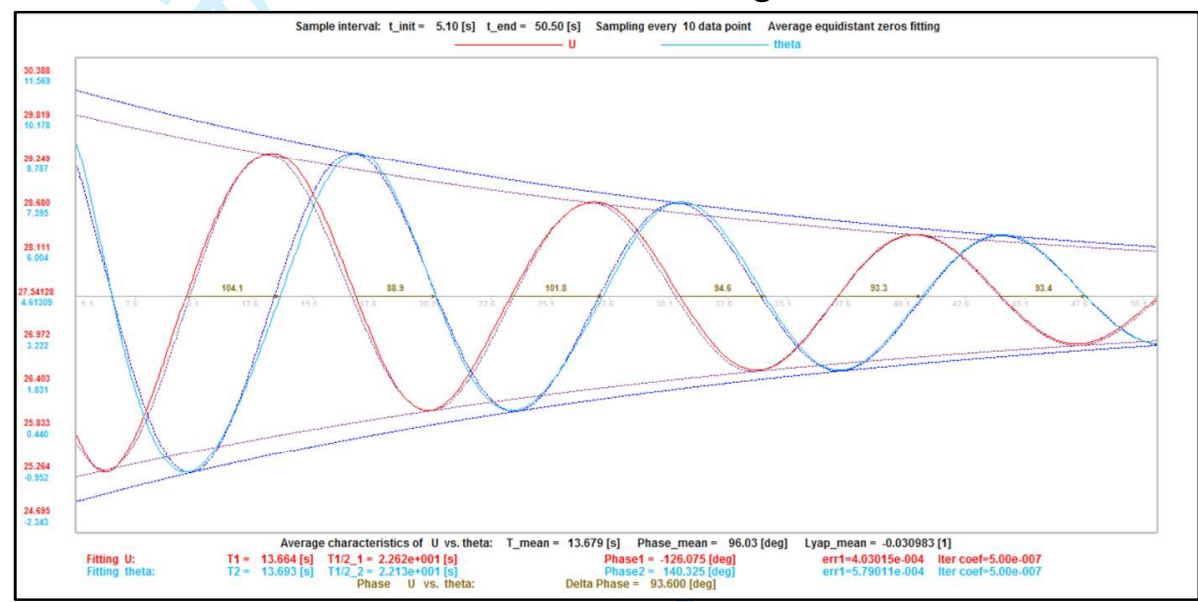

Table 3 Comparison of the results of the short period mode computed by SDSA and Matlab for $\delta e=-4$

36
37
38
39
40
41
42
43
44
45
46
47
48
49
50
51
52
53
54
5
56
57
58

\begin{tabular}{|c|c|c|c|c|}
\hline & Period & $\mathrm{T}_{1 / 2}$ & $\omega_{\text {nd }}$ & $\zeta_{0}$ \\
\hline SDSA: Standard case (1) & 0.476 & 0.1513 & 13.9724 & 0.3279 \\
\hline SDSA: Se impact on CDtrim only (2) & 0.487 & 0.1528 & 13.6761 & 0.3317 \\
\hline $\begin{array}{l}\text { SDSA: Se impact on derivatives and CDtrim } \\
\text { (3) }\end{array}$ & 0.481 & 0.17505 & 13.6497 & 0.2901 \\
\hline Difference between scenario (1) and (2) & $-2.3 \%$ & $-1.0 \%$ & $2.1 \%$ & $-1.2 \%$ \\
\hline Difference between scenario (1) and (3) & $-1.1 \%$ & $-15.7 \%$ & $2.3 \%$ & $11.5 \%$ \\
\hline $\begin{array}{l}\text { Matlab: } \delta \text { impact on derivatives and CDtrim } \\
\text { (3) }\end{array}$ & 0.4866 & 0.1427 & 13.7964 & 0.3522 \\
\hline
\end{tabular}

Table 4 Comparison of the results of the phugoid mode computed by SDSA and Matlab for $\delta e=-4$ Phugoid 


\begin{tabular}{|l|l|l|l|l|}
\hline SDSA: Standard case (1) & 12.141 & 16.37 & 0.5192 & 0.0815 \\
\hline SDSA: $\delta$ impact on CDtrim only (2) & 12.097 & 23.49 & 0.5202 & 0.0567 \\
\hline $\begin{array}{l}\text { SDSA: } \delta \text { impact on derivatives and CDtrim } \\
\text { (3) }\end{array}$ & 11.806 & 22.81 & 0.5331 & $-0.2 \%$ \\
\hline Difference between scenario (1) and (2) & $0.4 \%$ & $-39.3 \%$ & $-2.7 \%$ & $30.4 \%$ \\
\hline $\begin{array}{l}\text { Difference between scenario (1) and (3) } \\
\text { Matlab: } \delta e \text { impact on derivatives and CDtrim } \\
\text { (3) }\end{array}$ & 12.0493 & 22.842 & $30.1 \%$ & 0.5223 \\
\hline
\end{tabular}

\section{Conclusion}

- Derivatives changes, due to a geometry modification caused by elevons deflection are bigger than impact of the Mach number in case of a low speed

- In case of the Matlab analysis for scenarios (2) and (3), the biggest differences were noticed for the phugoid mode, especially for $\mathrm{T}_{1 / 2}$ and damping ratio.

- In case of the SDSA analysis, for all 3 scenarios the biggest differences were noticed for $T_{1 / 2}$ and damping ratio, especial for the phugoid mode the impact is very significant.

- The impact of the elevons deflection on the dynamic stability should be considered even for preliminary analysis as well as optimization process in case of analysis of tailless aircraft.

\section{Further Work}

The next step of the investigation, will be carried out studies, that takes into consideration change in the aircraft moment of inertia due to elevens deflection. And analysis of the lateral dynamic stability if a yaw channel is controlled by rotation of the tip wing side plates (working as an all moving tail).

\section{References}

Cook, M.V. (2007), Flight Dynamics Principles, Elsevier, Oxford

D'Urso S. and Martinez-Val R. (2008) "Flight Dynamics of the Flying Wing" 26th Congress of the International Council of the Aeronautical Sciences, Anchorage, Alaska, USA, Paper ICAS 2008-5.8.3

Esteban S., (2001) "Static and dynamic analysis of an unconventional plane - Flying wing", AIAA Atmospheric Flight Mechanics Conference and Exhibit Montreal, Canada, AIAA-2001-4010

Etkin, B. and Reid, L.D. (1996), Dynamics of flight. Stability and Control, John Wiley \& Sons Inc., New York, NY.

Figat M., Kwiek A. (2017), "Aerodynamic Optimisation of the Rocket Plane in Subsonic and Supersonic Flight Conditions", Proceedings of the Institution of Mechanical Engineers Part G Journal of Aerospace Engineering Vol.231, Issue 12, pp.2266-2281 
Galiński C., Mieloszyk J., (2012) "Results of the Gust Resistant MAV Programme", 28th Congress of the International Council of the Aeronautical Sciences, Brisbane, Australia, Paper ICAS 2012-3.1.1

Goetzendorf-Grabowski T., Mieszalski D.,Marcinkiewicz E., (2011),Stability analysis using SDSA tool, Progress in Aerospace Sciences, Vol. 47, Issue 8, November, pp. 636-646

Goetzendorf-Grabowski, T. and Figat, M. (2016), "Aerodynamic and stability analysis of personal vehicle in tandem-wing configuration", Proceedings of the Institution of Mechanical Engineers, Part G: Journal of Aerospace Engineering, Vol 231, Issue 11,pp. 2146-2162.

Goraj, Z. (2014) "Flight dynamics models used in different national and international projects", Aircraft Engineering and Aerospace Technology: An International Journal, Vol. 86 Issue: 3, pp.166-178,

Grafton S. B. (1984) „Low-Speed Wind-Tunnel Study of the High-Angle-of-Attack Stability and Control Characteristics of a Cranked-Arrow-Wing Fighter Configuration”, NASA Technical Memorandum 85776, Hampton, Virginia

Kwiek A., Figat M. (2016), "LEX and wing tip plates' interaction on the Rocket Plane in tailless configuration”, The Aeronautical Journal Vol. 120, Issue 1224, pp. 255-270

Mieloszyk J., Goetzendorf-Grabowski T., (2017), Introduction of full flight dynamic stability constraints in aircraft multidisciplinary optimization, Aerospace Science and Technology, 68 , pp. 252-260

Nelson, R. (1998), Flight stability and Automatic Control, McGraw-Hill, New York, NY.

Tomac M., Stenfelt G. (2014), "Predictions of stability and control for a flying wing”, Aerospace Science and Technology 39(2014)179-186

Panukl https://www.meil.pw.edu.pl/add/ADD/Teaching/Software/PANUKL, 2017

Rao D.M. (1979),"Leading Edge Vortex-Flap Experiments on a 74 deg. Delta Wing”, NASA Contractor Report 159161

SDSA https://www.meil.pw.edu.pl/add/ADD/Teaching/Software/SDSA , 2017

\section{Nomenclature}

\section{Symbols}

b- wingspan $[\mathrm{m}]$

$C_{D}-$ drag coefficient

$P, Q, R$ - angular velocities in body axis system [ $\mathrm{rad} / \mathrm{s}$ ]

$C_{L}-$ lift coefficient

$S$ - reference area $\left[\mathrm{m}^{2}\right]$

$\mathrm{CM}$ - pitching moment coefficient

$\mathrm{T}-$ period $[\mathrm{s}]$

g- gravity acceleration $\left[\mathrm{m} / \mathrm{s}^{2}\right]$

$\mathrm{T}_{1 / 2}$ - time to half damping [s]

ly - moment of inertia respect in body axis system [kg

$\mathrm{U}, \mathrm{V}, \mathrm{W}$ - speeds $[\mathrm{m} / \mathrm{s}]$

$\left.\mathrm{m}^{2}\right]$

$\mathrm{X}, \mathrm{Y}, \mathrm{Z}$ - force $\mathrm{X}, \mathrm{Y}, \mathrm{Z}$ components in body axis system [N]

$\mathrm{m}$ - mass $[\mathrm{kg}]$

$\mathrm{M}, \mathrm{N}, \mathrm{L}$ - aerodynamic moments in body axis system [Nm]

$\delta$ e - elevons (elevator) deflection [deg.]

$\omega_{\text {nd }}-$ undamped frequency

$\zeta_{d}$ - damping ratio

$\mathrm{MAC}$ - mean aerodynamic chord $[\mathrm{m}]$ 


\section{Definitions, Acronyms and Abbreviations}

Computational Fluid Dynamics (CFD) Unmanned Aerial Vehicles (UAV)

Simulation and Dynamic Stability Analysis (SDSA) 